\title{
A Case Study on the Eco-Efficiency Performance of a Composite Processing Industry: Evaluation and Quantification of Potential Improvements
}

\author{
M.C.S. Ribeiro, ${ }^{1}$, A.C.M. Castro ${ }^{1}$, F.J.G. Silva ${ }^{1}$, J.P. Meixedo ${ }^{1}$, L. Oliveira ${ }^{3}$, M.R. Alvim¹,
} A. Fiúza ${ }^{2}$ and M.L. Dinis ${ }^{2}$

${ }^{1}$ ISEP - School of Engineering, Polytechnic of Porto, Rua Dr. António Bernardino de Almeida, 4200-072 Porto, Portugal

${ }^{2}$ FEUP - Faculty of Engineering of University of Porto, Rua Dr. Roberto Frias, 4200-465 Porto, Portugal

${ }^{3}$ ALTO, Perfis Pultrudidos Lda., Maia, Portugal

\begin{abstract}
In this study, an attempt was made in order to measure and evaluate the eco-efficiency performance of a pultruded composite processing company. For this purpose the recommendations of World Business Council for Sustainable Development (WCSD) and the directives of ISO 14301 standard were followed and applied. The main general indicators of eco-efficiency, as well as the specific indicators, were defined and determined. With basis on indicators' figures, the value profile, the environmental profile, and the pertinent eco-efficiency ratios were established and analyzed.

In order to evaluate potential improvements on company eco-performance, new indicators values and eco-efficiency ratios were estimated taking into account the implementation of new proceedings and procedures, at both upstream and downstream of the production process, namely:

i) Adoption of a new heating system for pultrusion die-tool in the manufacturing process, more effective and with minor heat losses;

ii) Recycling approach, with partial waste reuse of scrap material derived from manufacturing, cutting and assembly processes of GFRP profiles.

These features lead to significant improvements on the sequent assessed eco-efficiency ratios of the present case study, yielding to a more sustainable product and manufacturing process of pultruded GFRP profiles.
\end{abstract}

Keywords: Pultrusion manufacturing company, Energy savings, Industrial wastes recycling, Eco-efficiency performance, Sustainability.

\section{INTRODUCTION}

The concept eco-efficiency was introduced for the first time in 1989 by Schaltegger and Sturm [1], and then launched and widely publicized by 'The World Business Council for Sustainable Development' (WBSD) in Changing Course [2]. According to this organization, 'eco-efficiency is achieved by the delivery of competitively-priced goods and services that satisfy human needs and bring quality of life, while progressively reducing ecological impacts and resource intensity throughout the life-cycle to a level, at least, in line with the Earth's estimated carrying capacity'. The term was aimed at summing up into a single expression the business end of sustainable development. Basically, it is about doing more with less: delivering more value while using fewer resources [2].

*Address correspondence to this author at the ISEP - School of Engineering, Polytechnic of Porto, Rua Dr. António Bernardino de Almeida, 4200-072 Porto, Portugal; Tel: +351 228340500; Fax: +351 228321159;

E-mail: cribeiro@inegi.up.pt
Though, eco-efficiency is not limited to making incremental efficiency improvements in existing practices and habits. It should stimulate creativity and innovation in the search for new ways of doing things. The concept has moved from preventing pollution in manufacturing industries to becoming a driver for innovation and competitiveness: while manufacturing processes are optimized, produced wastes are turned on into resources for other industries, driving innovation that leads to products with new functionalities [3].

Hence, implementing eco-efficiency in a company or business is first and foremost navigating for opportunities. Such opportunities can be found basically in four areas:

a) Re-engineering the processes aimed at reducing the consumption of resources, while at the same time saving costs;

b) Cooperating with other companies in order to revalorize by-products and production wastes, promoting recycling and the reuse of the recyclates into new added value products; 
c) Re-designing their products;

d) Finding new ways of meeting customer needs.

Within this scope, in the present case study, an attempt was made in order to predict and assess the potential improvements that could be made on the ecoefficiency performance of a local pultrusion manufacturing company - ALTO, Perfis Pultrudidos Lda. -, through re-engineering process and recycling approaches.

For this purpose all the issues involved in the manufacturing process of pultrusion profiles were analysed, the current eco-efficiency performance of the company was determined, all the procedures applied in the production process, as well as at upstream and downstream of the process were revised, and an improvement strategy was planned and investigated with basis on performed analysis.

\section{METHODOLOGIES}

\subsection{Eco-Efficiency Measurement}

Measuring the Eco-Efficiency of a company, factory or business is a complex process that involves the measurement and control of several and relevant parameters or indicators, globally applied to all companies in general, or specific according to the nature and specificities of the business itself. In this study, the recommendations of World Business Council for Sustainable Development (WCSD) [1] and the directives of ISO 14301 standard [4] were followed and applied. The main general indicators of eco-efficiency, as well as the specific indicators, were defined and determined according to ISO 14031 recommendations.
With basis on indicators' figures, the value profile, the environmental profile and the pertinent eco-efficiency ratios were established and analyzed.

The analysis was restricted to the main business branch of the company: the production and sale of standard glass fibre reinforced platic (GFRP) pultrusion profiles.

In the pultrusion process of $A L T O$, dry glass reinforcing fibres are pulled through a thermoset polyester resin bath for impregnation, and, after wetting process, the reinforcement is allowed to enter into a heated forming die, where it attains the shape of the die cavity and cures. The die is typically heated by external heaters as the most common heating system in pultrusion processes. Finally, outside the die, the composite part already consolidated is pulled by a continuous pulling system and then a cut-off saw cuts the part into a desired length. A schematic representation of pultrusion process is presented in Figure 1 and the main inputs and outputs of the pultrusion process of $A L T O$ are specified in Table 1. The time scale of the analysis was 75 working days and covered de production of seven different crosssection pultrusion profiles, illustrated ahead in this paper (Figure 2).

\subsection{Improvement Strategy Approaches}

In order to assess the potential improvements that could be made on eco-efficiency performance of the company, all the procedures involved in the production process were analysed and revised. It was found that it would be possible to improve eco-efficiency ratios taking action on two key fronts:

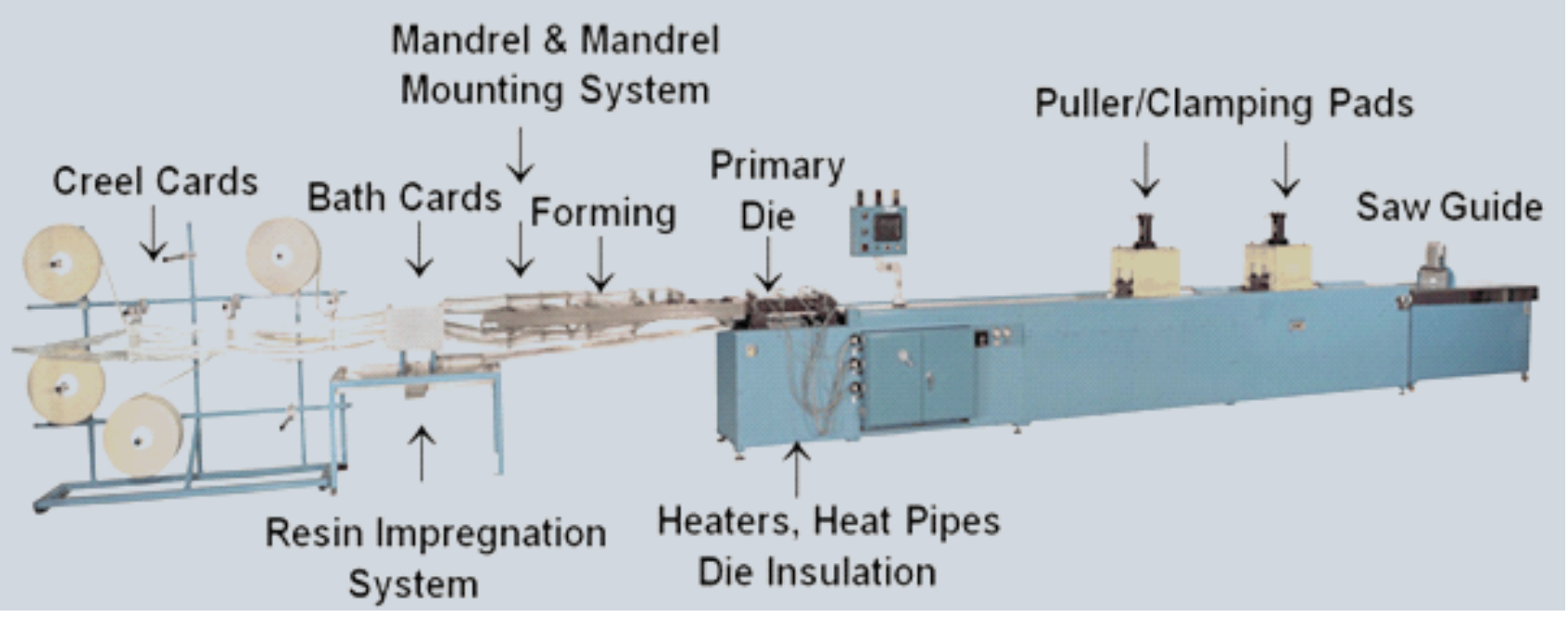

Figure 1: Schematic diagram of pultrusion process. 
Table 1: Main Inputs and Outputs of Pultrusion Manufacturing Process of ALTO

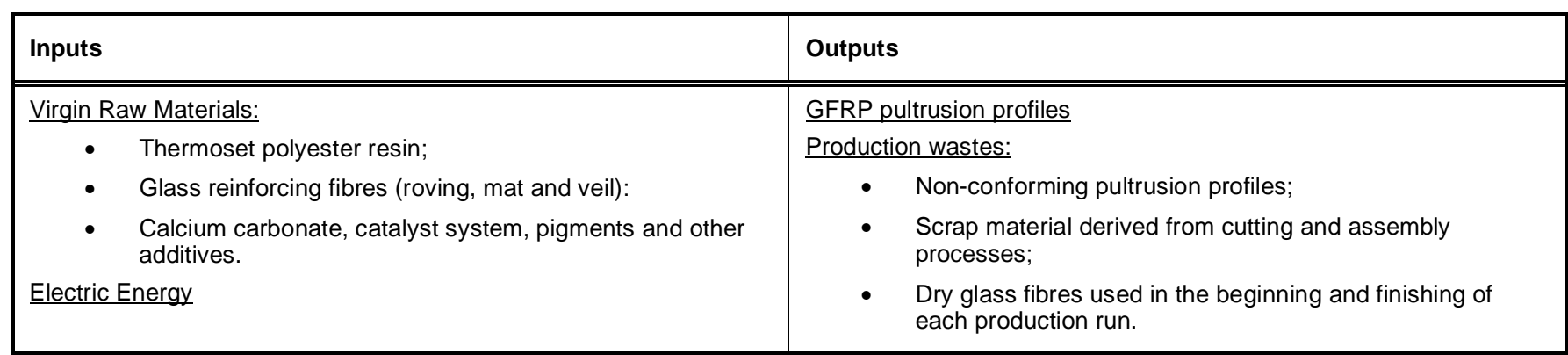

1) Re-engineering the manufacturing process, by optimization the heating die system and maximizing energy savings;

2) Recycling approach, with mechanical recycling of partial waste generated by manufacturing process and reuse of obtained recyclates either into a close-looping process or as raw materials for new added-value products.

\subsubsection{Re-Engineering Manufacturing Process in Order to Maximize Energy Savings}

Energy consumption is an important component of environmental impact and constitutes a critical issue in any overall sustainability strategy [5]. If manufacturing systems are managed to minimise energy usage, the operating costs are lowered and, on the other hand, the undesirable environmental impact from energy generation (carbon dioxide emissions) is reduced [6]. Though, there is still a strong inertia in the industrial organizations in changing procedures or adopting different technical approaches on their processes in order to reduce energy consumption and, hence, improve eco-efficiency ratios. Even small changes, especially on well-established and large scale manufacturing processes such as pultrusion, usually imply large investments with long-term outcomes. Thus, all measures to be proposed in this field must be based on strong and reliable assumptions.

Regarding the present case study, previous research showed that a significant reduction on energy consumption could be obtained using embedded cylindrical heaters into the die instead of the conventional external planar resistances. Experiments were conducted in a $900 \mathrm{~mm}$ length die during the manufacturing process of a standard pultrusion profile while keeping all the other process parameters constant: pulling speed, pulling force, total resistance power and temperature profile (TP) along the die. These process parameters were already fine-tuned by the large experience of the manufacturer, and conduct to a high standard of quality of pultruded part. TP was first experimentally obtained by thermography techniques, for the external heating system, and then numerically simulated by finite element analysis (FEA). After validation of FEA simulation, energy consumption with internal heating system was estimated using the same technique. Obtained results showed that internal resistances enhance significantly the energetic performance of pultrusion process, leading to $57 \%$ decrease of energy dispend in heating process, which represents a reduction of $17 \%$ of total energy consumed. A detailed explanation of conducted research study can be found in Silva et al. [7].

\subsubsection{Recycling Approach Involving Mechanical Recycling of GFRP Wastes e Posterior Reuse of Obtained Recyclates}

In the actual framework of the pultrusion sector, and in general in that of the composite materials' industry, production wastes and end-of life products are usually landfilled due to their limited recycling ability even when the thermoplastic-based products are considered. Hence, cooperation with other companies in order to revalorize by-products and production wastes, and promoting the recycling and the reuse of the recyclates into new added value products are critical and required steps towards a better eco-efficiency performance of this sector. Under this framework, the search for further sustainable materials have led that several recycling techniques have been analysed and proposed for FRP waste materials. A complete review of current recycling technologies for thermoset composites can be found in Pickering [8]. Thermal and/or chemical recycling methods with partial fibre and energy recovering have been proposed mostly for CFRP due to the inherent economic value of carbon fibre reinforcement; whereas for GFRP based products, mechanical recycling by shredding and milling processes with size reduction to fibrous and/or powdered products has been considered as a more economically viable recycling method. This last process presents important advantages over the 
former ones as follows: a) there is no atmospheric pollution by gas emissions; b) a much simpler equipment is required when compared with the ovens necessary for thermal recycling processes; and c) does not requires the use of chemical solvents with subsequent environmental impacts.

Mechanically recycled GFRP wastes remain however, somehow as 'beautiful little girls, well dressed, but no place to go', mired by the scarceness of cost-effective end-use applications and clearly developed recycling routes between both types of industries: waste producers and potential consumers for the recyclates. Over the last 20 years, several attempts have been made in order to solve this issue by putting considerable effort in the investigation of promising end-use applications for ground GFRP wastes. The most extensive research work has been carried out on Portland cement concrete in which mechanically recycled GFRP waste, and more rarely CFRP waste, have been incorporated either as reinforcement, aggregate or filler replacement [9-14]. In addition to environmental benefits, as function of specific mix design formulation, reported added values include slight to strong decreases of permeability with subsequent improved durability, less drying shrinkage, and a global cost reduction of raw materials. However, most of the times some undesirable features were also noticed such as significant losses in the mechanical properties (mainly due to high water-cement ratio required to achieve the desirable workability), higher wear loss, and weak adhesion at recyclate-binder interface. In addition, depending upon glass fibre nature, some incompatibility problems derived from alkalis silica-reaction may even occur. These limitations, by and large resultant from the use of a cementious binder as matrix, could be avoided using a cementless concrete as host material like polymer based concrete $(P C)$ materials.
Previous experimental work carried out by the present team [15] showed that GFRP recyclates can be successfully incorporated into polymer concrete based materials as reinforcement and partial replacement of aggregate components, leading to both flexural and compressive strength increases of modified concrete materials. The results highlighted a viable technological option for improving the quality of GFRP filled polymer concrete materials, thus opening a door to selective recycling of GFRP waste. It is expected that around $80 \%$ of actual production waste of Alto, corresponding to non-conforming profiles and scrap material derived from cutting processes, could be mechanically recycled and reduced to fibrous/filler material, and posteriorly reused either as reinforcement for polymer concrete based materials or as partial calcium carbonate replacement of resin matrix in the pultrusion process.

The above actions will drive to minimization of waste landfill and costs reduction in both raw materials and landfill process.

\section{RESULTS}

Measured value and environmental indicators are presented in Figure 2. Presented values are discriminated according to the 7 types of pultrusion profiles produced by the company during the framework time. They include the 4 general value and environmental indicators and 1 business-specific indicator of environmental influence (total of production waste and by-products to landfill).

With basis on obtained indicators, current ecoefficient ratios were determined and compared with those that could be obtained implementing the improvement strategy approaches:

- The use of an internal die heating system instead of the conventional one of multi-planar heaters;

Table 2: Obtained Eco-Efficient Ratios for the Actual Proceedings and Expected Eco-Efficient Ratios Taking into Account the Implementation of the New Procedures

\begin{tabular}{|c|c|c|c|}
\hline Eco-Efficient Ratios & Current values & Expected values & Improvement \\
\hline \hline Mass of product sold per: & & & \\
Energy consumption; & $17.58 \mathrm{~kg} / \mathrm{kWh}$ & $21.18 \mathrm{~kg} / \mathrm{kWh}$ & $20.5 \%$ \\
Materials consumption; & $0.89 \mathrm{~kg} / \mathrm{kg}$ & $0.93 \mathrm{~kg} / \mathrm{kg}$ & $5.4 \%$ \\
Total waste disposal. & $13.91 \mathrm{~kg} / \mathrm{kg}$ & $69.54 \mathrm{~kg} / \mathrm{kg}$ & $400.0 \%$ \\
Net sales per: & $174.53 \mathrm{Eur} / \mathrm{kWh}$ & $210.28 \mathrm{Eur} . / \mathrm{kWh}$ & $20.5 \%$ \\
Energy consumption; & $8.80 \mathrm{Eur} . / \mathrm{kg}$ & $9.27 \mathrm{Eur} . / \mathrm{kg}$ & $5.4 \%$ \\
Materials consumption; & $138.10 \mathrm{Eur} . / \mathrm{kg}$ & $690.49 \mathrm{Eur} . / \mathrm{kg}$ & $400.0 \%$ \\
Total waste disposal. & & \\
\hline
\end{tabular}



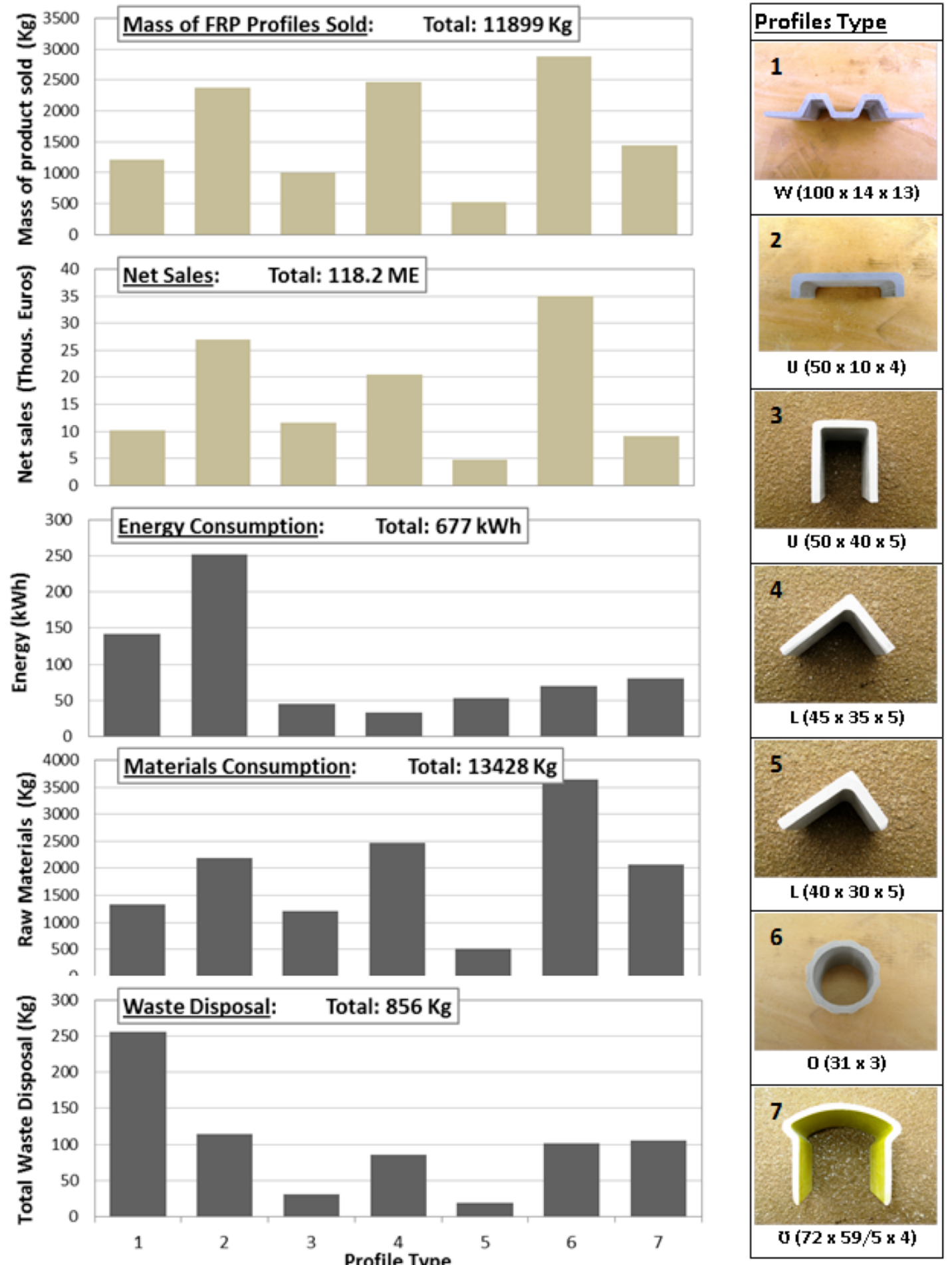

Figure 2: Value and environmental indicators presented by profile type produced by the company during the framework time (left). Type of GFRP pultrusion profiles (cross-section dimensions in $\mathrm{mm}$ ) analysed in this case study (right).

- Mechanical recycling and reuse of scrap materials and non-conforming pultrusion profiles, either as reinforcement into new composite materials or into a close-looping process, as calcium carbonate replacement for resin matrix of GFRP profiles.
Obtained results are presented in Table 2.

\section{CONCLUSIONS}

Mechanical recycling approach, with partial waste reuse of scrap material derived either from manufacturing or cutting and assembly processes of 
GFRP profiles, as well as the implementation of a new heating system for pultrusion die, will drive to both costs reduction in raw materials, energy and landfill process, and minimization of waste disposal.

These features lead to significant improvements on the sequent assessed eco-efficient ratios of the present case study, yielding to a more sustainable product and manufacturing process of pultruded GFRP profiles.

\section{ACNOWLEDGEMENTS}

The technical support of ALTO, Perfis Pultrudidos $L d a$., and the financial support of 'ADI, Agência de Inovação' under National Strategic Reference Framework (NSRF) are gratefully acknowledged.

\section{REFERENCES}

[1] Schaltegger S, Sturm A. Okologie-induzierte entscheidungsprobleme des managements. Ansatzpunkte zur augestaltung von instrumenten (Ecology induced management decision support. Starting points for instrument formation). WWZ-Dissertation paper no ${ }^{-8914}$, University of Basel, Switzerland 1989.

[2] Schmidheiny S. Changing Course - A Global Business Perspective on Development and the Environment, BCSDBusiness Council for Sustainable Development. London: The MIT Press 1992.

[3] Lehni M. Eco-Efficiency: Creating more value with less impact. WBCSD Report, World Business Council for Sustainable Development 2000.

[4] ISO 14031:1999. Environmental Management Environmental Performance Evaluation - Guidelines. ISO Standard, International Organization for Standardization 1999.

[5] Franco A, Romoli L. Characterization of laser energy consumption in sintering of polymer based powders. J Mater Process Tech 2012; 212: 917-26.

http://dx.doi.org/10.1016/j.jmatprotec.2011.12.003
[6] Pusavec F, Krajnik P, Kopac J. Transitioning to sustainable production - Part I: Application on machining technologies. J Clean Prod 2010; 18: 174-84. http://dx.doi.org/10.1016/i.jclepro.2009.08.010

[7] Silva FJG, Ferreira F, Costa C, Ribeiro MCS, Castro ACM Comparative study about heating systems for pultrusion process. Compos Part B-Eng 2012; 43: 1823-9. http://dx.doi.org/10.1016/i.compositesb.2012.01.057

[8] Pickering SJ. Recycling technologies for thermoset composite materials - current status. Compos Part A-Appl S 2006; 37: 1206-15. http://dx.doi.org/10.1016/j.compositesa.2005.05.030

[9] Asokan P, Osmani M, Price ADF. Assessing the recycling potential of glass fibre reinforced plastic waste in concrete and cement composites. J Clean Prod 2009; 17: 821-9. http://dx.doi.org/10.1016/j.jclepro.2008.12.004

[10] Asokan P, Osmani M, Price ADF. Improvement of the mechanical properties of glass fibre reinforced plastic waste powder filled concrete. Const. Build Mater 2010; 24: 448-60. http://dx.doi.org/10.1016/..conbuildmat.2009.10.017

[11] Tittarelli F, Moriconi G. Use of GRP industrial by-products in cement based composites. Cement Concrete Comp 2010 32: $219-25$

http://dx.doi.org/10.1016/j.cemconcomp.2009.11.005

[12] Correia JR, Almeida NM, Figueira JR. Recycling of FRP composites: Reusing fine GFRP in concrete mixtures. J Clean Prod 2011; 19: 1745-53. http://dx.doi.org/10.1016/j.jclepro.2011.05.018

[13] Osmani M, Pappu A. An assessment of the compressive strength of glass reinforced plastic waste filled concrete for potential applications in construction. Concrete Res Lett 2010; 1: 1-5.

[14] Ogi K, Shinoda T, Mizui M. Strength in concrete reinforced with recycled CFRP pieces. Compos Part A-App S 2005; 36 893-902. http://dx.doi.org/10.1016/j.compositesa.2004.12.009

[15] Ribeiro MCS, Fiúza A, Castro ACM, et al. Recycling of Pultrusion Production Waste into Innovative ConcretePolymer Composite Solutions. Adv Mater Res 2011; 295-7: $561-5$.

\section{DOl: http://dx.doi.org/10.6000/1929-5995.2013.02.01.9}

(c) 2013 Ribeiro et al.; Licensee Lifescience Global.

This is an open access article licensed under the terms of the Creative Commons Attribution Non-Commercial License (http://creativecommons.org/licenses/by-nc/3.0/) which permits unrestricted, non-commercial use, distribution and reproduction in any medium, provided the work is properly cited. 